\title{
COMPOSTEIRA PEDAGÓGICA: UMA PROPOSTA DE MATERIAL DIDÁTICO PARA ABORDAGEM DA TEMÁTICA VERMICOMPOSTAGEM NO ENSINO DE QUÍMICA
}

\author{
Denise gomes da silva costa \\ Instituto Federal de Santa Catarina - IFSC - Câmpus São José (Brasil) \\ deniseg9000@hotmail.com · https://orcid.org/0000-0003-1400-3694 \\ Paula Alves de Aguiar \\ Instituto Federal de Santa Catarina - IFSC - Câmpus São José (Brasil) \\ paula.alves.aguiar@gmail.com · https://orcid.org/0000-0003-0776-9472
}

\begin{abstract}
Resumo. Este texto apresenta um relato de experiência da prática de estágio curricular supervisionado do curso de Licenciatura em Química do IFSC/SJ em uma turma do Ensino Médio. A experiência em questão consiste na elaboração e no desenvolvimento do projeto "Vermicompostagem na escola: construção do conhecimento e sustentabilidade visando à valorização da comunidade escolar", cujas principais etapas são descritas, com o intuito de trazer ao leitor as relações processuais inerentes à realização desse mesmo projeto. De outra parte, neste trabalho também se buscou evidenciar o processo de elaboração e desenvolvimento de um material didático, como mediador pedagógico entre o aluno e o conhecimento. Dessa forma, o objetivo principal deste texto é apresentar a composteira pedagógica utilizada para abordagem da temática 'Vermicompostagem no ensino de Química', identificando suas contribuições para o alcance de aprendizagens mais significativas de acordo com os pressupostos assumidos na elaboração do projeto em questão, dentre os quais estão os dos Projetos Criativos Ecoformadores. Considerações sobre a experiência também são feitas a partir do relato de percepções subjetivas dos momentos da interação teórica e prática proporcionados pela mediação da composteira pedagógica; bem como por meio da apresentação de dados elencados a partir de dois questionários aplicados durante a regência. A partir disso, evidencia-se que a proposta e o recurso didático trabalhado proporcionaram um processo de ensino-aprendizagem significativo e prazeroso. Nas relações entre os sujeitos, houve indícios de que os alunos se mostraram motivados e protagonistas no processo educativo.
\end{abstract}

Palavras-chave: Ensino de Química, Material Didático, Estágio Supervisionado.

\section{PEDAGOGICAL COMPOSTER: A PROPOSAL OF DIDACTIC MATERIAL TO ADDRESS THE THEME VERMICOMPOSTING IN THE TEACHING OF CHEMISTRY}

\begin{abstract}
This article gives an account of an experience of the supervised curricular internship practice of the IFSC / SJ Degree in Chemistry in a high school class. The main stages of the experience are described, which deals with the preparation and development of the project 'Vermicomposting in school: Knowledge construction and sustainability aiming at valuing the school community', so that the reader can learn about the procedural relationships inherent to its accomplishment. Furthermore, this work sought to demonstrate the process of elaboration and development of a didactic material, as pedagogical mediator between the student and the knowledge. Thus, this text has as main objective to present the pedagogical composter used to address the theme "Vermicomposting" in the teaching of Chemistry, identifying how it contributed to obtain a more meaningful learning according to the assumptions adopted in the elaboration of the given project, among which the Ecoforming Creative Projects stand out. The article includes considerations about
\end{abstract}


the experience from the subjective standpoints of the moments of theoretical and practical interaction provided by the mediation of pedagogical composter, as well as the presentation of data extracted from two questionnaires applied during the regency. Taking this into account, it is emphasized that the proposal and didactic resource with which they worked provided a process of teaching-learning as significant as enjoyable. The evidence from the relations between the subjects shows the students motivated and protagonists in the educational process.

Keywords: Teaching Chemistry, Didactic Material, Supervised Internship.

\title{
COMPOSTERA PEDAGÓGICA: UNA PROPUESTA DE MATERIAL DIDÁCTICO PARA ABORDAR EL TEMA VERMICOMPOSTAJE EN LA ENSEÑANZA DE LA QUÍMICA
}

\begin{abstract}
Resumen. Este documento reporta la experiencia de la pasantía curricular supervisada de la Licenciatura en Química del IFSC / SJ en una clase de escuela secundaria. Se describen las principales etapas de la experiencia, que trata de la preparación y el desarrollo del proyecto "Vermicompostaje en la escuela: construcción del conocimiento y sostenibilidad con el objetivo de valorar a la comunidad escolar", para que el lector pueda tomar conocimiento de las relaciones de procedimiento inherentes a su realización. Por otro lado, este trabajo también buscó demostrar el proceso de elaboración y desarrollo de un material didáctico, como mediador pedagógico entre el alumno y el conocimiento. Por lo tanto, este texto tiene como finalidad presentar la compostera pedagógica utilizada para abordar el tema "Vermicompostaje" en la enseñanza de la química, identificando cómo contribuyó a obtener un aprendizaje mas significativo de acuerdo con los presupuestos adoptados en la elaboración del proyecto en cuestión, entre los cuales se destacan los Proyectos Creativos Ecoformadores. El artículo incluye consideraciones sobre la experiencia desde los puntos de vista subjetivos de los momentos de interacción teórica y práctica proporcionados por la mediación de la compostera pedagógica, así como la presentación de datos extraídos de dos cuestionarios aplicados durante la regencia. Teniendo esto en cuenta, se enfatiza que la propuesta y el recurso didáctico con el que trabajaron proporcionaron un proceso de enseñanza-aprendizaje tan significativo como agradable. En las relaciones entre los sujetos, se indica que los estudiantes se mostraron motivados y asumieron el protagonismo en el proceso educativo.
\end{abstract}

Palabras clave: Enseñanza de la Química, Material Didáctico, Pasantia Supervisada.

\section{Introdução}

A prática de estágio curricular supervisionado do curso Licenciatura em Química do Instituto Federal de Santa Catarina - campus São José (IFSC/SJ) teve como um de seus desdobramentos a oportunidade de escrita do presente artigo. Nele, pretende-se relatar a experiência de elaboração e desenvolvimento do projeto de intervenção 'Vermicompostagem na escola: Construção do conhecimento e sustentabilidade visando à valorização da comunidade escolar', aplicado em 2018, durante o estágio de regência em Química da primeira autora, com uma turma do $1^{\circ}$ ano do Ensino Médio da Escola de Educação Básica Francisco Tolentino, do município de São José, Santa Catarina, Brasil.

Como norteadora do processo de elaboração e sistematização do projeto em questão, tem-se a metodologia dos Projetos Criativos Ecoformadores (PCE) (Torre, 
Zwierewicz, 2009), a qual tem sido utilizada, desde 2015, como um dos referenciais na proposta de organização dos projetos de intervenção dos estágios do curso mencionado (Aguiar, Pereira e Viella, 2017). Logo, neste texto, optou-se por assumir, no decorrer da escrita, somente o termo PCE, para referir-se ao projeto de intervenção relatado.

Buscar alternativas didático-metodológicas, bem como adotar abordagens contextualizadas que tornem conteúdos curriculares atrativos e de fácil entendimento é fundamental no processo de ensino-aprendizagem de qualquer disciplina escolar. Contudo, faz-se ainda mais importante quando os alunos apresentam histórica e tradicionalmente maior dificuldade no processo de apropriação do conhecimento, conforme diagnosticado em determinadas disciplinas escolares do Ensino Médio, como a de Química (Lima, 2012).

Tendo isso em vista, também fez parte dos aportes teóricos na elaboração do projeto, a concepção de que o processo de ensino-aprendizagem de Química requer estratégias e metodologias tomadas a partir da dimensão dos saberes com sentido para os estudantes. Nessa perspectiva, igualmente considerou-se o papel da contextualização do conhecimento, procurando assim, a construção de significados presentes no cotidiano de quem aprende. Sobre isso, Lima (2012, p. 99) faz as seguintes considerações:

Qualquer que seja a concepção metodológica a ser seguida, os saberes desenvolvidos no ensino de Química devem ser fundamentados em estratégias que estimulem a curiosidade e a criatividade dos estudantes, despertando sua sensibilidade para a inventividade e compreendendo que esta ciência e seus conhecimentos permeiam a sua vida, estando presentes nos fenômenos mais simples do seu cotidiano.

$\mathrm{Na}$ assunção desses aspectos, por meio do projeto, buscou-se efetivar os propósitos de ensino contextualizado de Química, via abordagem da temática 'Vermicompostagem na escola'. Além disso, para proporcionar a mediação pedagógica da temática escolhida, e propiciar aos alunos contato direto com aspectos práticos da proposta idealizada, fez-se uso de um Material Didático (MD). Que MD é esse? Uma composteira pedagógica (CP), cujo processo de construção e utilização durante o desenvolvimento do projeto é igualmente relatado e discutido neste texto, a partir dos diferentes aportes teóricos que embasaram a experiência em questão.

No processo de idealização do MD, levou-se em conta a complexidade do ato de aprender, considerando que este é um processo presente na vida de toda pessoa, geralmente relacionado às experiências e interações de cada um. Em estudo de caráter teórico, Rocha e Vasconcelos (2016, p. 2) trazem algumas reflexões sobre o ato de aprender e sua vinculação "... ao desenvolvimento global: corpo, mente, inteligência, sensibilidade, sentido ético ...", abordando sob esta perspectiva as dificuldades de aprendizagem no ensino de Química e, por conseguinte, alguns meios para possibilitar o ensino de forma contextualizada, problematizadora e dialógica. Segundo as autoras,

... pode-se dizer que a motivação para estudar e aprender química, pode ser alcançada com a elaboração de um material didático que seja potencialmente significativo (itálico adicionado), permitindo a integração entre o conhecimento prévio do aluno , o chamado subsunçor, e a nova informação apresentada pelo professor, que juntos produzirão um conhecimento potencialmente significativo (Rocha e Vasconcelos, 2016, p. 8).

Dessa maneira, a intenção de discutir a experiência da elaboração e aplicação da CP do PCE é devido ao fator potencialmente significativo para o processo de ensinoaprendizagem, vinculado ao ato de aprender no sentido global. 
Considerando o exposto e as reflexões emergentes no decorrer desta introdução, pretende-se evidenciar interações entre os sujeitos envolvidos na vivência do projeto. E, também a motivação dos alunos ao serem protagonistas no processo de ensinoaprendizagem. Portanto, tem-se como principal objetivo deste artigo: apresentar o processo de construção e elaboração da composteira pedagógica como material didático no ensino de Química para abordagem da temática 'Vermicompostagem na escola', identificando suas contribuições para alcançar aprendizagens mais significativas de acordo com pressupostos assumidos na elaboração do projeto em questão, dentre os quais estão os dos PCEs. Contudo, considera-se necessário apresentar ao leitor, primeiramente, aspectos processuais - teóricos, pedagógicos e metodológicos - relacionados à elaboração e desenvolvimento do projeto como um todo.

\section{O projeto 'Vermicompostagem na escola': um breve relato de sua elaboração e desenvolvimento}

Para elaboração do projeto relatado e discutido neste texto, houve uma primeira etapa: o estágio de observação. Nela foram realizadas observações participantes ${ }^{i}$ na escola campo do estágio, estabelecendo-se relações entre os sujeitos envolvidos - alunos, professor supervisor e estagiária - como também com o espaço e a comunidade escolar. Com essas observações, foi possível realizar levantamento de informações - por meio de registros em diários de campo; da análise do Projeto Político Pedagógico da escola e de entrevistas com alguns integrantes da comunidade escolar - que viabilizaram a elaboração de uma proposta de ensino de Química contextualizada, partindo dos interesses e possibilidades daquele espaço educativo.

No fechamento dessa etapa, partindo da pesquisa como princípio educativo nas práticas de estágio, realizou-se uma atividade do tipo roda de conversa. Esta estratégia metodológica “... permite a interação entre o pesquisador e os participantes da pesquisa por ser uma espécie de entrevista de grupo ...”, a qual consiste em “... uma discussão focada em tópicos específicos na qual os participantes são incentivados a emitirem opiniões sobre o tema de interesse ..." (Melo e Cruz, 2014, p. 33). Por meio dessa atividade, então, além dos aspectos já citados, buscou-se indícios para avaliar possíveis alternativas de ensino-aprendizagem de Química para além da sala de aula, bem como elementos para sistematização do projeto na perspectiva do PCE. Para isso, realizaramse discussões com propósito de identificar opiniões dos alunos sobre a relação do conhecimento químico com fenômenos e situações do cotidiano. A partir da utilização de algumas imagens, procurou-se discutir o 'lugar' da química na escola, assim como o que se estuda/aprende e onde se pode estudar/aprender Química, expondo-se ideias acerca do dilema do ponto de vista do conhecimento científico - localizado no laboratório, e o utilitário - localizado nas coisas do cotidiano (Rosa e Tosta, 2006). Por meio dos pressupostos apresentados, foi então fomentado com os alunos o entendimento da "química do cotidiano" como espaços e/ou situações que podem ser vistas como sistemas a serem explicados por conceitos científicos, como é o caso da vermicompostagem.

O resultado processual das vivências no estágio de observação e da atividade de roda de conversa foi a elaboração e sistematização do projeto, na perspectiva da metodologia do PCE, com a intencionalidade de:

a) trabalhar o entorno, aproximando a escola da vida real; b) valorizar todas as disciplinas ...; c) oportunizar um trabalho com metodologia ativa, aberta ao novo, ao 
debate, à reflexão, pesquisa e ação; d) provocar todos os agentes na resolução dos problemas oriundos da realidade ambiental (Mallart, 2009 apud Pukall, Silva e Silva, 2017. p.31).

Além de ações que propiciassem a efetivação das intenções referidas por Mallart (2009 apud Pukall, Silva e Silva, 2017), outros elementos norteadores da construção do projeto foram: adoção de alternativas didático-metodológicas diferenciadas; abordagens contextualizadoras, que tornassem os conteúdos curriculares atrativos e de fácil entendimento; ensino de Química voltado para formação de cidadãos(ãs) conscientes e críticos(as); e desenvolvimento de um processo de ensino-aprendizagem que extrapolasse a sala de aula.

No que se refere à escolha da temática, "Vermicompostagem na escola: Construção do conhecimento e sustentabilidade visando à valorização da comunidade escolar', esta foi pautada na perspectiva da Educação Ambiental Crítica, que, segundo Marcos Reigota (1994, p.14), um dos grandes ambientalistas do Brasil,

... deve ser entendida como educação política, no sentido de que ela reivindica e prepara os cidadãos e as cidadãs para exigir e construir uma sociedade com justiça social, cidadanias (nacional e planetária), autogestão e ética nas relações sociais e com a natureza.

Tendo todos estes aspectos em vista, o projeto propôs a reciclagem dos resíduos orgânicos sólidos produzidos pela cantina da escola, por meio da implementação de uma composteira no local. Dessa forma, indo ao encontro das diretrizes do Projeto Político Pedagógico da E.E.B. Francisco Tolentino, e promovendo ações para o programa 'Continuar o Projeto Reciclando o Lixo', também previsto neste documento. As ações para tal fim, promovidas durante a realização do projeto, visaram proporcionar aos alunos a construção de conhecimentos químicos e de Educação Ambiental Crítica, de forma significativa e prazerosa, tornando-os protagonistas no processo de ensino-aprendizagem e agentes colaboradores na transformação da comunidade escolar.

A técnica utilizada para reciclagem dos resíduos orgânicos sólidos da escola e para contextualizar os conteúdos químicos foi a da vermicompostagem, que é um processo controlado de compostagem com minhocas. O método consiste em caixas sobrepostas, sendo simples e de baixo custo; não atrai insetos e não causa mau cheiro e requer um pequeno espaço ventilado e protegido (Francelin e Cáceres, 2014), adequado para o ambiente escolar.

Segundo menciona Dal Bosco (2017, p. 15):

Com a publicação da Lei n. 12.305/2010, que estabeleceu a Política Nacional de Resíduos Sólidos, estratégias como a compostagem e a vermicompostagem ganharam destaque para o tratamento de resíduos, visando à minimização do uso de espaços em aterros sanitários, a eliminação de passivos ambientais e a transformação de um resíduo em material com valor agregado, que pode ser utilizado como adubo para o solo.

Sendo assim, a vermicompostagem, além de evitar diversos impactos socioambientais provenientes do descarte inadequado dos resíduos orgânicos sólidos, também gera produtos que podem ser utilizados na melhoria do ambiente escolar, como é o caso do biofertilizante líquido e do húmus de minhocas - adubo orgânico - que podem ser usados no jardim e em uma possível horta. 
$\mathrm{Na}$ contextualização temática, surgiu o desafio de relacionar o tema 'Vermicompostagem na escola' à aprendizagem da Química, conforme conteúdos programáticos previstos para o bimestre da regência. De que forma minhocas e resíduos orgânicos poderiam ser relacionados com o estudo sobre substâncias químicas inorgânicas (ácidos, bases, sais e óxidos) e reações químicas afins? Para esta articulação, assumiu-se o entendimento de que a técnica de compostagem com minhocas poderia ser vista como um sistema a ser estudado a partir de conceitos da Química, considerando que, no processo de degradação da matéria orgânica pelas minhocas e microrganismos, estão presentes transformações físico-químicas. Dessas transformações são originados compostos ricos em nitrogênio, fósforo, potássio e substâncias húmicas, que podem ser usadas como adubo para o solo, mudando as características químicas deste e influenciando, assim, o desenvolvimento das plantas.

Partindo-se, então, deste entendimento e desta possibilidade de articulação entre a temática e os conteúdos de Química, foi elaborada uma sequência didática com 17 aulas, organizadas e desenvolvidas conforme apresentado na Tabela 1, a seguir.

\section{Tabela 1}

Cronograma das aulas, destacando os conteúdos de Química trabalhados, a articulação com a temática, a utilização da composteira pedagógica, a aplicação dos questionários e outras atividades desenvolvidas

\begin{tabular}{cc}
\hline Aula & Atividades desenvolvidas e/ou conteúdos abordados \\
\hline 01 & Epítome \\
\hline 02 & Substâncias químicas inorgânicas - Relações com "Vermicompostagem" \\
\hline 03 & Óxidos - Relação entre compostagem, aterros sanitários e efeito estufa \\
\hline $04-05$ & Continuação de óxidos - Primeira intervenção com a CP \\
\hline 06 & Segunda intervenção com a CP \\
\hline 07 & Ácidos e bases - Relação com resíduos orgânicos adequados para composteira \\
\hline 08 & Trabalho de pesquisa \\
\hline 09 & Continuação de pH - Acidez e basicidade dos solos com disponibilidade de nutrientes para \\
as plantas - Terceira intervenção com a CP
\end{tabular}

Ao assim organizar o ensino, teve-se como objetivo geral do PCE: proporcionar um processo de ensino-aprendizagem que ultrapassasse os limites da sala de aula, fomentando a compreensão de conceitos químicos para melhor leitura de mundo, especificamente, no que se refere à reciclagem de resíduos orgânicos; bem como a valorização da comunidade escolar. Indo ao encontro do objetivo geral, procurou-se responder às seguintes perguntas geradoras: "Qual o melhor destino para os resíduos orgânicos composteira ou lixão? Por quê?" e, "De que maneira a utilização do húmus de minhocas e do biofertilizante líquido provenientes da composteira interferem nas propriedades e na constituição química do solo? É para melhoria da qualidade do solo? Por quê? 
Conforme apresentado na tabela acima, a primeira aula da sequência didática foi caracterizada como epítome, que é um dos organizadores conceituais da metodologia do PCE. Ele foi a primeira etapa de desenvolvimento do projeto, consistindo em uma ação voltada ao 'encantamento' dos alunos pela temática a ser abordada. De acordo com Zwierewicz (2014, p.69), “... a atividade consiste na aproximação da proposta com os estudantes implicados no projeto. Ela caracteriza o ponto de partida, a âncora, o entorno de interação entre teoria e prática e, portanto, entre a ciência e a realidade".

Para alcançar o propósito do epítome, idealizou-se uma atividade intitulada "Piquenique de Ideias", realizada ao ar livre no jardim da escola, onde os participantes sentaram-se em círculo e degustaram frutas, enquanto a discussão sobre o tema do projeto era introduzida (Figura 1), por meio de perguntas problematizadoras e utilizando-se uma das imagens discutidas na roda de conversa realizada no estágio de observação. Qual seja: a imagem 'terra com minhocas', com alusão à temática e à questão sobre o que se estuda/aprende e onde se pode estudar/aprender Química. Durante esse momento realizaram-se contextualizações pertinentes envolvendo o espaço físico - jardim da escola - e aspectos relacionados à composição do solo, degradação da matéria orgânica e função das minhocas nesse processo. Procurou-se estabelecer relações entre os resíduos orgânicos gerados pela degustação das frutas e as consequências da escolha do descarte desses mesmos resíduos, composteira ou aterro sanitário, viabilizando introdução dos conceitos da técnica vermicompostagem.

Após esse processo dialógico de construção de conhecimentos, a turma foi organizada em quatro grupos, e foram distribuídos entre eles pedaços de papel pardo, canetões e figuras em material EVA de: minhocas, casca de banana, maçã comida, folhas verdes e elementos químicos (magnésio, cálcio, potássio, fósforo e nitrogênio). Foi, então, solicitado que registrassem no papel pardo - por meio de palavras, frases, desenhos, colagens das figuras - suas impressões, indagações, pensamentos, ideias, considerações em relação ao que foi conversado durante a atividade. Os cartazes produzidos (Figura 1) pelos alunos foram colocados no mural da sala de aula e serviram de apoio didático nas aulas seguintes. Para finalizar o epítome, foram distribuídos aos alunos doces em formato de minhocas, com o objetivo de 'mexer' com a relação de 'nojo', geralmente existente.
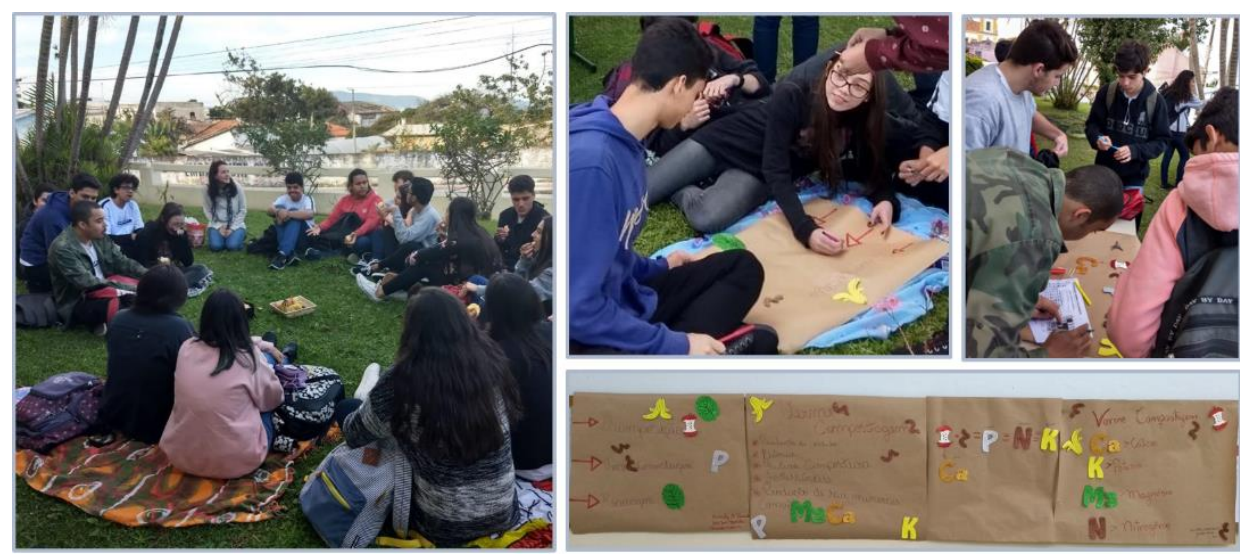

Figura 1. Primeira aula - Epítome.

Fonte: elaboração das autoras (2019) 
A partir de uma avaliação da reação dos estudantes à atividade proposta, pode-se dizer que o epítome alcançou seus objetivos, pois em geral eles mostraram-se animados, curiosos e envolvidos com a temática proposta, querendo conhecer mais sobre o que seria desenvolvido no projeto.

Perante a perspectiva teórico-metodológica do PCE, não apenas no epítome, mas ao longo de todas as outras 16 aulas procuraram-se proporcionar momentos de participação ativa e interações entre os sujeitos envolvidos no processo de ensinoaprendizagem. Estes aconteceram, sobretudo, nas aulas em que houve intervenções com a composteira pedagógica $(\mathrm{CP})$, utilizada como $\mathrm{MD}$, cujo processo de construção e aplicação será apresentado na próxima seção.

\section{Composteira Pedagógica como material didático no ensino de Química: premissas e utilização no projeto 'Vermicompostagem na escola'}

O curso de Licenciatura em Química do IFSC-SJ propõe aos licenciandos que, durante o processo de sistematização de cada PCE, elaborem seus próprios MDs a serem utilizados no estágio de regência. Segundo Freitas (2009, p. 21), MDs são "recursos" ou "tecnologias educacionais" que surgiram ao longo da história da educação a fim de facilitar o processo de ensino-aprendizagem, “... visando à estimulação do aluno e à sua aproximação do conteúdo ...”. Contudo, conforme destacado por Borges (2000), é preciso que os MDs sejam compreendidos para além de meros auxiliares nas atividades de ensino. Para o autor, mais que suportes físicos de veiculação ou transmissão de alguma mensagem/informação, eles são expressões "da relação forma/conteúdo, definidos a partir de concepções de ensino-aprendizagem" (Borges, 2000, p. 180). Nesse sentido, destaca-se a concepção de MD como mediador pedagógico, ou seja, mediador nas relações entre professores, alunos e conhecimento, com o objetivo de "... proximar o aluno da realidade e do conhecimento que se quer ensinar, facilitando a percepção e compreensão de conceitos ...” (Borges, 2000, p.185).

Tendo isso em vista, após a escolha da temática do projeto, surgiu o desafio de se pensar em um MD que pudesse mediar a contextualização dos conteúdos químicos de forma prazerosa e atrativa, tornando os alunos protagonistas do processo. Que MD poderia ser este? A partir de pesquisas sobre a técnica de vermicompostagem, chegouse, então, à descoberta de um modelo de $\mathrm{CP}$ comercializado na internet, que inspirou a criação de uma variante com materiais alternativos - ou seja, reutilizados, acessíveis e de baixo custo - previamente confeccionada e testada.

Para confecção do material em questão, utilizou-se duas garrafas pets transparentes de água mineral de cinco litros e uma tampa plástica de lata de leite ou similar (Figura 2). Na montagem, as garrafas pets foram recortadas, a tampa plástica foi perfurada para dar passagem ao biofertilizante (parte líquida), assim como a tampa de cima para ventilação e montada de acordo com a Figura 3, representando o sistema de caixas sobrepostas. 

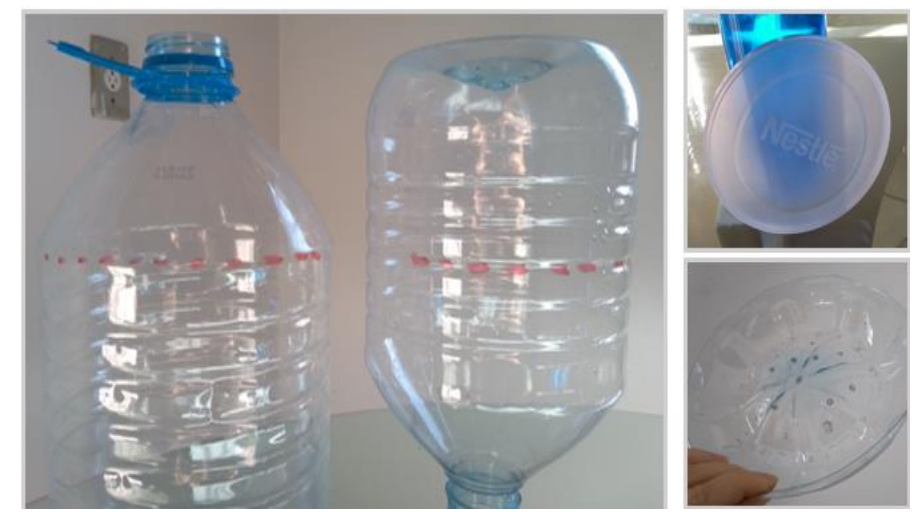

Figura 2. Material alternativo para confecção da CP. Fonte: acervo das autoras (2019).

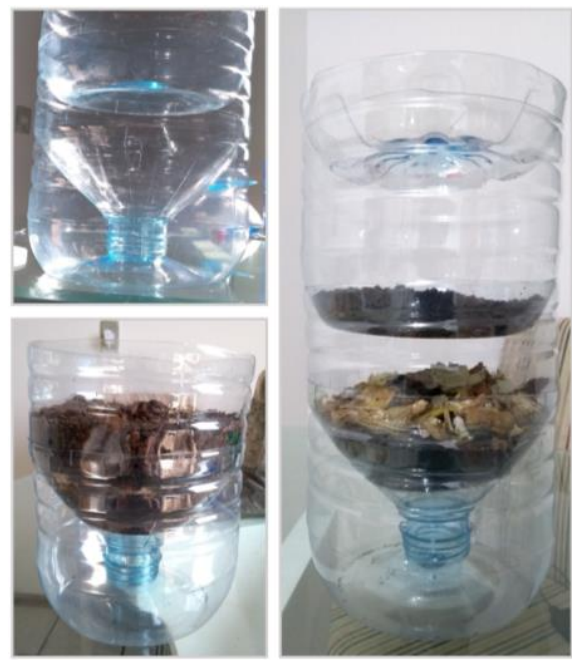

Figura 3. Montagem da CP. Fonte: acervo das autoras (2019).

Assim confeccionada, a CP foi então testada, a partir do acompanhamento de seu funcionamento ao longo de algumas semanas. Nesse processo, pôde-se avaliar a viabilidade de sua utilização no PCE, bem como organizar a proposta de sua construção em sala de aula, pelos próprios alunos. Dessa forma, visou-se a vivência da técnica de vermicompostagem em suas próprias composteiras, acompanhando in loco as etapas do processo de degradação da matéria orgânica em húmus de minhocas e biofertilizante.

A CP promoveu experiências significativas durante o estágio de regência, proporcionando o estabelecimento de relações processuais ${ }^{\mathrm{ii}}$ entre os envolvidos, conforme relatado e sistematizado a seguir, a partir das percepções da primeira autora sobre a reação dos estudantes acerca dos momentos de intervenção com o MD em questão.

\section{Primeiro momento}

Na aula 04-05 da sequência didática, conforme identificado na Tabela 1, foram iniciadas as vivências práticas com o MD, apresentando-se para os alunos a proposta de utilização e confecção da $\mathrm{CP}$ e sua relação com o projeto. Essa parte compreendeu em trabalhos manuais, realizados em parceria com o professor de Arte da escola, durante as aulas desta disciplina escolar. Inicialmente, realizou-se aporte teórico em sala de aula, enfatizando os objetivos da CP como material didático, e a divisão da turma em quatro 
grupos, seguido dos trabalhos propriamente ditos no laboratório de Ciências da escola, previamente preparado para as atividades.

Nele estavam todo material necessário para confecção das peças a serem utilizadas na montagem do MD (Figura 4): as garrafas pets preparadas para os recortes, tampas de lata de leite em pó, cola, tesoura, tinta e a CP confeccionada para teste. Os procedimentos e divisão das tarefas dos integrantes dos grupos estavam descritos no quadro, onde também foi disposto banner com esquema de uma composteira com minhocas para auxiliar na visualização do funcionamento. Os alunos estavam animados e envolvidos na atividade, e dedicaram-se com apreço na confecção da CP.

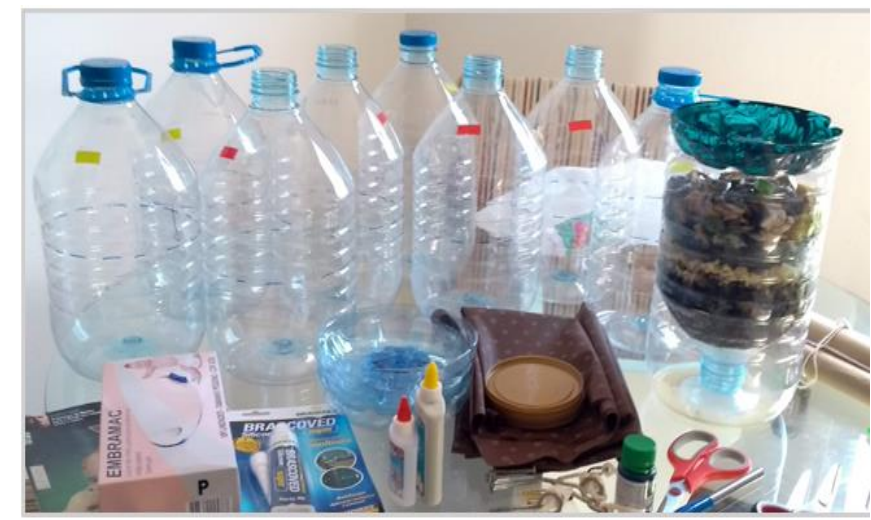

Figura 4. Material utilizado para confecção das peças das CPs. Fonte: acervo das autoras (2019).

\section{Segundo momento}

$\mathrm{Na}$ aula 06, os alunos conheceram as minhocas californianas e os grupos montaram, com os materiais preparados na primeira intervenção, suas respectivas CP. Após aporte teórico em sala de aula, as atividades práticas foram realizadas novamente no laboratório de Ciências, previamente preparado. Em geral, os alunos sentiram-se à vontade para manipular as minhocas. Apesar de alguns estudantes manifestarem 'nojo', elas foram bem aceitas e propiciaram interações prazerosas. Após montagem final das CPs, com a devida alocação das minhocas, os grupos foram orientados sobre a disposição dos resíduos orgânicos. Nessa atividade, os alunos vivenciaram na prática os conceitos da técnica de vermicompostagem e, por meio da montagem da $\mathrm{CP}$, tornaram-se protagonistas no processo de ensino-aprendizagem.

\section{Terceiro momento}

Esta terceira intervenção com a CP ocorreu após dez dias da montagem , na $10^{\mathrm{a}}$ aula, tendo como objetivo observar mudanças ocorridas no sistema. Também foi previamente solicitado aos grupos que levassem para a sala de aula resíduos orgânicos para manutenção da CP. Alguns alunos levaram de suas casas, outros dispuseram de resíduos orgânicos da cozinha da escola. Sendo encaminhados para o laboratório de Ciências 20 minutos antes do término da aula, estavam ansiosos e animados para rever as suas CPs e saberem como as minhocas estavam. Por meio das observações, verificaram que houve degradação da matéria orgânica com princípio de formação de húmus. Além disso, perceberam que o sistema apresentava sinais de 'suor', indicando reações do tipo exotérmica e que não exalava odor desagradável. Cada equipe adicionou matéria orgânica na sua $\mathrm{CP}$. 


\section{Quarto momento}

Foi realizado oito dias depois da anterior, na $14^{\mathrm{a}}$ aula. Os alunos realizaram novas observações e fizeram manutenção da matéria orgânica, que levaram de suas casas ou da cozinha da escola. Nesse momento, algumas equipes verificaram produção de biofertilizante ('chorume do bem'), demonstrado na Figura 5, o que gerou grande satisfação, pois puderam vivenciar na prática um dos resultados da compostagem com minhocas.

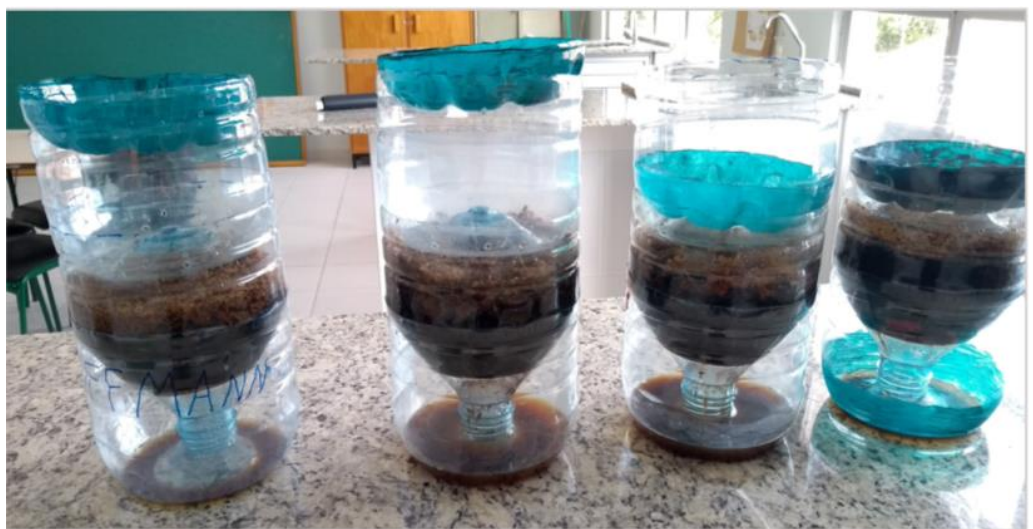

Figura 5. Composteiras dos grupos. Fonte: acervo das autoras (2019).

\section{Quinto momento}

Dentro da metodologia do PCE, a polinização é a etapa na qual os resultados do projeto são socializados e difundidos, por meio de ações que propiciem a outros sujeitos acesso à proposta desenvolvida. Dessa forma, ideias e valores trabalhados pelos alunos na temática são disseminados, oportunizando propagação e desenvolvimento em outros contextos (Zwierewicz, 2014).

No intuito de alcançar a perspectiva da polinização, foi realizado evento no auditório, na $17^{\mathrm{a}}$ aula, envolvendo a comunidade escolar, representada pelos: professores de Ciências, Física e Química; alunos do Ensino Fundamental; diretor da escola e o presidente da Associação de Pais e Professores (APP). Sintetizando, a polinização desenvolveu-se por meio das seguintes ações: apresentação da proposta do PCE; explicações sobre a técnica vermicompostagem realizadas por representantes da turma com auxílio de um banner com informações básicas, apresentação da CP pelos alunos com relato de experiências e aprendizados construídos em relação a temática (Figura 6); e por fim, a concretização da reciclagem de resíduos orgânicos sólidos na escola, por meio da apresentação e montagem de uma composteira adquirida pela APP da escola ante discussões feitas a partir da realização do projeto.

Na última ação da polinização, os presentes foram convidados a participarem da atividade, que constituiu na transferência das minhocas e húmus das CPs para composteira da escola, e no processo de alocar os resíduos orgânicos, previamente separados pela responsável da cantina. Esse momento foi o ápice das relações entre os sujeitos envolvidos no evento (Figura 7), pois proporcionou interação e arremate da difusão dos resultados do PCE. A composteira da escola foi acondicionada no refeitório juntamente com banner. 


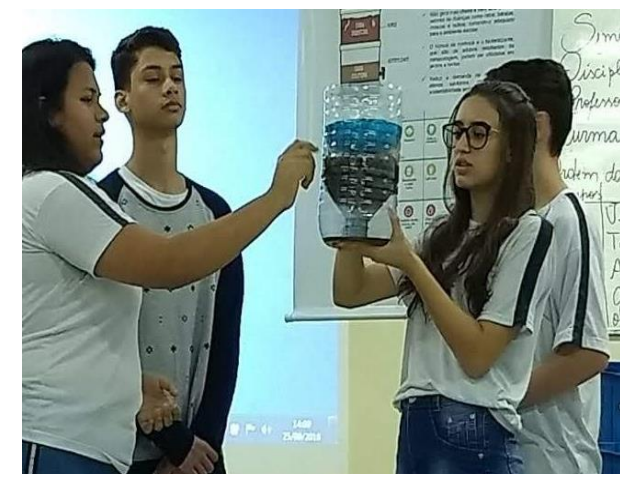

Figura 6 Explicações sobre a temática por meio da CP. Fonte: acervo das autoras (2019).

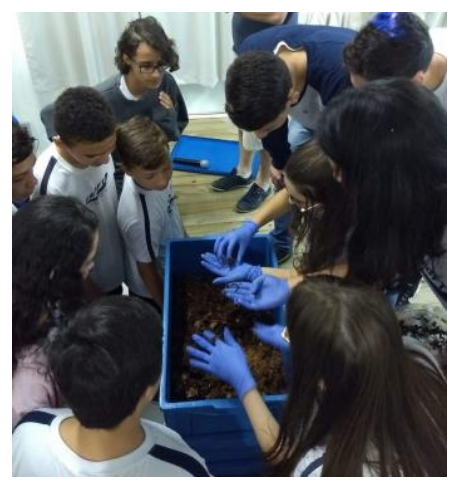

Figura 7. Interação entre sujeitos e temática do projeto. Fonte: acervo das autoras (2019).

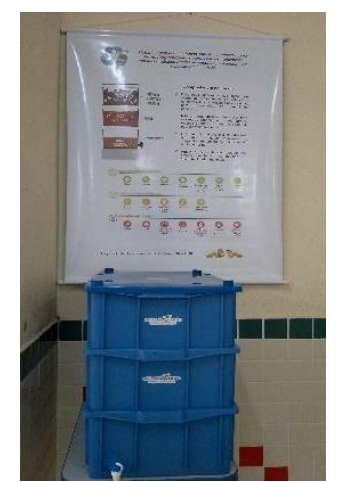

Figura 8. Composteira da escola alocada. Fonte: acervo das autoras (2019).

A utilização da $\mathrm{CP}$, durante a polinização, permitiu que fossem retratadas vivências práticas do processo de ensino-aprendizagem proporcionado pelo projeto. Além disso, possibilitou que os sujeitos que estavam tendo contato pela primeira vez com a temática, pudessem visualizar o processo prático da compostagem com minhocas, indo além das questões teóricas.

\section{Tabela 2}

Atividades com as CPs e percepções da primeira autora em relação à reação dos estudantes, durante os momentos de confecção e utilização do MD

\begin{tabular}{lll}
\hline \multicolumn{1}{c}{ Momentos } & \multicolumn{1}{c}{ Atividades com as CPs } & \multicolumn{1}{c}{ Percepções } \\
\hline Primeiro momento & $\begin{array}{l}\text { Apresentação da proposta do MD e } \\
\text { confecção das peças para montagem das } \\
\text { CPs. }\end{array}$ & $\begin{array}{l}\text { Alunos animados e envolvidos com a } \\
\text { proposta. }\end{array}$ \\
\hline Segundo momento & $\begin{array}{l}\text { Contato com as minhocas e montagem } \\
\text { das CPs. }\end{array}$ & $\begin{array}{l}\text { Interação prazerosa e significativa, } \\
\text { aluno protagonista na construção do } \\
\text { conhecimento. }\end{array}$ \\
\hline Terceiro momento & $\begin{array}{l}\text { Observação com percepções físico- } \\
\text { químicas do sistema e manutenção da } \\
\text { matéria orgânica. }\end{array}$ & $\begin{array}{l}\text { Alunos animados e envolvidos com a } \\
\text { técnica de vermicompostagem, } \\
\text { construindo conhecimentos químicos } \\
\text { pela contextualização temática. }\end{array}$ \\
\hline Quarto momento & $\begin{array}{l}\text { Novas observações e manutenção da } \\
\text { matéria orgânica. }\end{array}$ & $\begin{array}{l}\text { Satisfação com os resultados práticos da } \\
\text { CP. }\end{array}$ \\
\hline Quinto momento & $\begin{array}{l}\text { Difusão dos resultados do projeto por } \\
\text { meio da polinização e implantação da } \\
\text { composteira da escola. }\end{array}$ & $\begin{array}{l}\text { Envolvimento da comunidade escolar } \\
\text { com a proposta do projeto. }\end{array}$ \\
\hline
\end{tabular}

Nota: Elaboração própria (2019)

\section{Contextualização temática e a Composteira Pedagógica sob o olhar dos alunos}

Para obter informações para além das percepções subjetivas da primeira autora, e assim avaliar a perspectiva metodológica e as atividades realizadas a partir do olhar dos alunos, foram aplicados dois questionários: um quase na metade do desenvolvimento do projeto e outro, ao final (ver Tabela 1).

Para registro das percepções e observações resultantes das intervenções com a CP, foi entregue para cada grupo, na $11^{\mathrm{a}}$ aula, um material impresso, contendo perguntas referentes às atividades desenvolvidas nos três primeiros momentos. As perguntas foram 
elaboradas no sentido de obter opiniões, bem como identificar os conhecimentos construídos nos processos de (I) preparação das peças para montagem da CP; (II) confecção das CPs; (III) manutenção de seu funcionamento, obtendo-se os seguintes resultados:

As respostas sobre procedimentos de preparação das peças, que seriam usadas para montagem da $\mathrm{CP}$, indicaram: conhecimento dos materiais utilizados; apropriação dos procedimentos desta etapa do processo; atividade clara e compreensível, destacandose respostas elogiando a aula por ter sido "diferente e muito divertida".

As respostas sobre o momento em que os alunos montaram as CPs indicaram: apropriação de como construir um sistema fechado de compostagem com minhocas, com identificação da função de cada parte de uma composteira; receptividade no manuseio das minhocas; conhecimento sobre matéria orgânica sólida, própria para técnica em questão.

As respostas sobre o momento de observação do sistema, após dez dias da montagem e funcionamento das CPs, indicaram: percepção e conhecimento das mudanças no sistema; conhecimento dos procedimentos de manutenção; imersão na técnica de vermicompostagem com afirmações de que "o reencontro foi ótimo", "conseguimos compostar", "as minhocas estavam vivas", "a composteira estava suada", "a matéria tinha sido consumida".

De acordo com os resultados deste primeiro processo avaliativo, pode-se identificar aspectos que corroboram com percepções subjetivas da primeira autora deste trabalho, oriundas das relações processuais descritas na Tabela 2. Dessa forma, há indícios de que a CP contribuiu para o alcance dos objetivos do PCE. Os indícios são: alunos imersos na temática proposta, motivados e alegres durante o processo educativo mediado por um MD potencialmente significativo (Rocha e Vasconcelos, 2016).

O segundo questionário foi individual e anônimo, contendo três perguntas discursivas e cinco objetivas, sendo aplicado na $17^{\mathrm{a}}$ aula, último dia da regência, e respondido por 28 alunos. $\mathrm{O}$ objetivo do questionário foi obter feedbacks referentes às atividades desenvolvidas como um todo ao longo das regências, bem como avaliar a atuação da licencianda. O que cabe destacar nesse questionário, por ter relação com discussões do presente trabalho, são as considerações relativas à contextualização temática e aos procedimentos didáticos como alternativas significativas no processo de ensino-aprendizagem, conforme se pode depreender das respostas a seguir:

Aluno 1 - “...as aulas foram divertidas e muito dinâmicas, além de termos aprendido muito sobre compostagem e óxidos, base e ácidos ...".

Aluno 2 - "As dinâmicas, ela é super dinâmica e faz com que a gente veja o que estava estudando". carinho".

Aluno 3 - "O mais legal foi a composteira e ensinou muito a gente, obrigado pelo

Aluno 4 - "As aulas fora da sala, a confecção das composteiras com minhocas..., repleto de aprendizados". divertido".

Aluno 5 - "A parte da gente fazer atividades práticas, pois é mais legal e

Aluno 6 - "Eu achei todas as aulas interessantes e divertidas".

Mediante as respostas, acredita-se que o projeto desenvolvido, na perspectiva da metodologia dos PCE, propiciou alternativas didático-metodológicas e abordagem 
contextualizada que tornaram os conteúdos curriculares atrativos e de fácil entendimento. Além disso, evidenciam a concepção da $\mathrm{CP}$ como mediador pedagógico no processo de ensino-aprendizagem, facilitando percepções e compreensão de conceitos (Borges, 2000). Portanto, indo ao encontro de soluções para o diagnóstico apresentado por Lima (2012) em relação ao ensino de Química.

Outro aspecto que pode ser inferido a partir de respostas é que, em seu desenvolvimento, o PCE aqui relatado aproximou-se do ensino de Química voltado para formação de cidadãos conscientes e críticos, visando uma interação melhor com o mundo proveniente da ampliação da capacidade de leitura do entorno em que se encontra (Chassot, 1990, Santos e Schnetzler, 2003):

Aluno 7 - "A composteira, porque aprendemos muitas coisas e a reciclar, também podemos levar esse aprendizado para nossa casa, e também aprendemos sobre base e ácidos".

Aluno 8 - "O encaminhamento da compostagem. Porque é de grande ajuda para o povo, importante na reciclagem de resíduos orgânicos".

Aluno 9 - "Mais interessante foi o método de compostagem, porque ajuda o planeta como um todo".

No referente à articulação do projeto com a perspectiva da Educação Ambiental Crítica (Reigota, 1994), além das respostas mencionadas, em outras encontra-se o estabelecimento de relações entre o aprendido e o desenvolvimento de uma preocupação ambiental:

Aluno 10 - "Foi importante aprendermos sobre a vermicompostagem porque aprendemos a importância de podermos ajudar o meio ambiente e os animais, com a reciclagem de frutas e legumes e podermos ajudar as plantas com a compostagem".

Aluno 11 - "Acredito que podemos usar bem os resíduos, gostei muito disso porque as sobras de comida não precisamos jogar fora, e sim alimentar as minhocas".

Aluno 12 - "Achei muito interessante a parte da vermicompostagem, pois posso fazer uma em qualquer lugar (a composteira)".

Em uma pergunta objetiva relativa à adequação de recursos didáticos e técnicas de ensino ao conteúdo, aos objetivos e ao nível da turma, as respostas variaram de "bom" a "ótimo", conforme Figura 9:

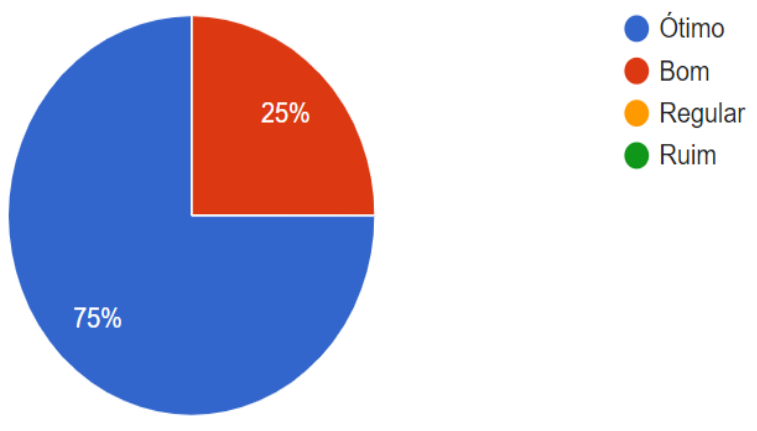

Figura 9. Gráfico pergunta objetiva. Fonte: segundo questionário aplicado aos alunos. 
Essa pergunta, em seu sentido amplo, abrange avaliação da $\mathrm{CP}$ na função de material didático do PCE desenvolvido, adequado aos conteúdos, aos objetivos e ao nível da turma. Dessa forma, a leitura do gráfico apresentado indica satisfação dos alunos em relação aos MDs (Freitas, 2009), utilizados na construção processual do projeto.

\section{Considerações finais}

Considerando a experiência realizada, compreende-se que o ensino de Química pode, de fato, propiciar aprendizagens significativas e prazerosas a partir da contextualização de conceitos químicos com atividades práticas, tendo em vista o relato e os resultados do projeto 'Vermicompostagem na escola'. Neste caso, a peculiaridade do projeto foi a adaptação da complexidade de uma técnica específica para algo possível de ser demonstrado e vivenciado em sala de aula. Por meio da construção de suas próprias CPs, possibilitou-se aos alunos que realizassem e acompanhassem a degradação da matéria orgânica, no que se refere às mudanças físico-químicas ocorridas durante a formação das substâncias húmicas - húmus de minhocas e biofertilizante líquido.

Incluso na compreensão, os MDs por si só não possibilitam uma aprendizagem significativa, mas sim a forma como são articulados no processo educativo e ao planejamento e objetivos do professor, como visto na experiência relatada no texto. A fim de ampliar a discussão, Cunha e outros (2015, p. 191) apontam o fator “... motivador para os professores, principalmente os licenciados em estágio inicial da profissão, para que haja uma percepção no transmitir e mediar os conteúdos e conceitos da disciplina de Química de uma maneira mais integrada e contextualizadas com suas vivências ...".

Acredita-se que a construção da referida compreensão se faz, sobretudo, importante no processo de formação inicial de professores, quando o que se almeja é a formação de docentes crítico-reflexivos, como também pesquisadores e transformadores da realidade. Dessa forma, capacitados para pensar e agir em prol da superação do desinteresse e das dificuldades no processo de apropriação dos conhecimentos químicos, tendo em vista que esses profissionais são mediadores nesse processo.

Nesse sentido, as propostas formativas dos cursos de Licenciatura em Química têm a responsabilidade de viabilizar estratégias e experiências significativas na formação do futuro professor de Química. Formação esta que requer muito mais do que apreensão de conhecimentos químicos, tendo em vista as considerações feitas até aqui sobre ensinoaprendizagem em Química, nas escolas de ensino médio. Corroborando com as inquietações apresentadas sobre a formação docente, Lima (2012, p.6) registra que "Muitos cursos de licenciatura espalhados por todo território começam a sofrer reformulações. Esses cursos, que antes eram atrelados aos bacharelados, começam a assumir identidade própria (itálico adicionado). Isso demonstra uma expectativa de mudanças na formação do professor de química".

Perante o exposto, salienta-se o papel da estrutura e concepção dos estágios curriculares tanto no processo de formação da identidade do futuro professor, quanto no processo dos cursos de Licenciatura assumirem uma identidade própria, conforme referido por Lima (2012). Acredita-se que este seja o caso do curso de Licenciatura em Química do IFSC/SJ, no qual a metodologia do PCE faz parte de sua proposta curricular. Além disso, oferece uma diversidade de práticas em prol da formação do professor crítico reflexivo, mas também pesquisador e transformador da realidade, em prol da dinâmica 
do conhecimento e das relações que fortalecem o saber docente. Nesse aspecto, destacase o estágio supervisionado percorrido como experiência formadora e transformadora, mediante os aportes teóricos e as práticas vivenciadas (Aguiar e outros, 2019).

\section{Referências}

Aguiar, P. A., Drews, F., Demos, T. V., Pereira, G. A. e Vaz, K. (2019). Estágios Supervisionados na Formação Docente: Experiências e Práticas do IFSC-SJ. Florianópolis: Publicações do IFSC.

Aguiar, P. A., Pereira, G. A. e Viella, M. A. L. (2017). O uso da metodologia dos Projetos Criativos Ecoformadores (PCE) no estágio curricular supervisionado de um curso de licenciatura do Instituto Federal de Santa Catarina (IFSC) câmpus São José. Revista Professare, 6(2), 123-140.

Borges, G. L. A. (2000). Formação de Professores de Biologia, Material Didático e Conhecimento Escolar. 440f. Tese (Doutorado em Educação). Campinas: Universidade Federal de Campinas.

Chassot, A. I. (1990). A educação no ensino da química. Ijuí: Ed. Universidade Regional do Noroeste do Estado do Rio Grande do Sul.

Cunha, F. S. e outros. (2015). Produção de material didático em ensino de Química no Brasil: Estudo a partir da análise das linhas de pesquisas CAPES e CNPq. HOLOS, 31(3), 182-192.

Dal Bosco, T. C. (Org) (2017). Compostagem e vermicompostagem de resíduos sólidos: resultados de pesquisas acadêmicas. São Paulo: Ed. Edgard Blücher Ltda.

Francelin, L. P. e Cortez, A. T. C. (2014). Compostagem: por uma escola mais sustentável. Ciência Geográfica, XVIII, 116-130.

Freitas, O. (2007). Os equipamentos e materiais didáticos. Brasília: Universidade de Brasília. Centro de Educação a Distância. Recuperado em 20 de abril de 2018, de http://portal.mec.gov.br/seb/arquivos/pdf/profunc/equipamentos.pdf.

José O. G. L. (2012). Perspectivas de novas metodologias no Ensino de Química. Revista Espaço Acadêmico, 136, 95-101.

Lima, José Ossian Gadelha. (2012). Perspectivas de novas metodologias no Ensino de Química. Revista Espaço Acadêmico. Revista Espaço Acadêmico, (136), 95-101. http://www.educadores.diaadia.pr.gov.br/arquivos/File/setembro2013/quimica_a rtigos/perspect_novas_metod_ens_quim.pdf.

Melo, M. C. H. e Cruz, G. (2014). Roda de Conversa: Uma Proposta Metodológica para a Construção de um Espaço de Diálogo no Ensino Médio. Imagens da Educação, 4(2), 31-39.

Pukall, J. P., Silva, V. L. S. e Silva, A. R. (2017). Projetos criativos Ecoformadores na educação básica: uma experiência em formação de professores na perspectiva da criatividade. Blumenau: Nova Letra.

Reigota, M. (1994). O que é Educação Ambiental. São Paulo: Brasiliense. 
Rocha, J. S. e Vasconcelos, T. C. (2016). Dificuldades de aprendizagem no ensino de química: algumas reflexões. XVIII Encontro Nacional de Ensino de Química ENEQ.

Rosa, M. I. P. e Tosta, A. H. (2006). O lugar da Química na escola: Movimentos Constitutivos da disciplina no cotidiano escolar. Ciência \& Educação, 11(2), 253262.

Santos, W. L. P. e Schnetzler, R. P. (2003). Educação em Química: compromisso com a cidadania. Ijuí: Unijuí.

Tura, M. L. R. (2003) A observação do cotidiano escolar. Zago, N., Carvalho, M. P. e Vilela, R. A. T. (Orgs.) Itinerários de pesquisa. Perspectivas qualitativas na Sociologia da Educação (pp. 183-205). Rio de Janeiro: DP\&A.

Torre, S. e Zwierewicz, M. (2009). Projetos Criativos Ecoformadores. M, Zwierewicz e e S. Torre (Coord.). Uma escola para o século XXI: escolas criativas e resiliência na educação (pp. 153-175). Florianópolis: Insular.

Zwierewicz, M. (2014), Seminário de pesquisa e intervenção I. Florianópolis: Publicações do IFSC.

\footnotetext{
' Consiste em uma prática de pesquisa caracterizada pela interação entre o pesquisador/observador e as atividades do grupo de interação, considerando o observador mais ativo (TURA, 2003).

ii Vínculo que se estabelece e une gradualmente os sujeitos inseridos em um processo, decorrente de ações em comum (nota da primeira autora).
}

Data da recepção: $27 / 07 / 2019$

Data da revisão: 22/10/2019

Data do aceite: 23/10/2019 